Pacific Journal of Mathematic 


\title{
ON MATRICES HAVING THE SAME CHARACTERISTIC EQUATION
}

\author{
Elmar F. OSBORNe
}

1. Introduction. Let $A$ and $B$ be $n \times n$ matrices whose elements lie in an infinite perfect ${ }^{1}$ field $F$. Alfred Brauer [1] and W. V. Parker [2] have considered the question: "When do $A$ and $B$ have the same characteristic equation?" Their results have been sufficiency conditions with special forms of $A$ and $B$. W. T. lieid [3] has considered a related problem.

The present paper is concerned with the following theorem that contains the results of brauer and l'arker as special cases.

THEOREM. A necessary and sufficient condition for matrices $A$ and $B$ to have the same characteristic equation is that there exist a nonsingular matrix $P$ (with elements in $F)$ such that for $N=1-P^{-1} B P$ :

ivery polynomial $g$ in $A$ and $N$, each term of which contains $N$ at least once, is nilpotent.

iie introduce a special canonical form in $\$ 2$ and give the proof in $\$ 3$.

2. Canonical forms. For any matrix $A$, there exists a nonsingular matrix $P_{1}$, with elements in $F$, such that

$$
P_{1}^{-1} A P_{1}=A_{1}+A_{2}+\cdots+A_{k},
$$

where the characteristic equation of $A_{i}$ is $\left[p_{i}(x)\right]^{\alpha_{i}}=0$, and $p_{i}(x)$ is an irreducible polynomial over $F$. Woreover, for each $A_{i}$ we have the decomposition by the nonsingular matrix $P_{2 i}$ with elements in $F$ :

$$
P_{2 i}^{-1} A_{i} P_{2 i}=A_{i 1}+A_{i 2}+\cdots+A_{i k_{i}} \text {, }
$$

in which each $A_{i \mu}$ is nonderogatory with characteristic equation $\left[p_{i}(x)\right]^{\alpha_{i \mu}}=0$ and is of the form $[4, \mathrm{p} .750]$

\footnotetext{
${ }^{1}$ Every irreducible equation over $F$ is separable.
}

Received June 21, 1951. The author gratefully acknowledges the encouragement and suggestions of Professor Lowell J. Paige of the University of California, Los Angeles, in the preparation of this paper.

Pacific J. Math. 2 (1952), 227-230 


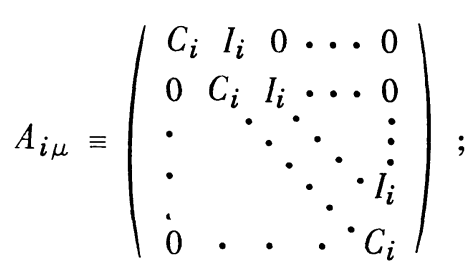

where $C_{i}$ is the companion matrix of $p_{i}(x)$, and occurs $\alpha_{i \mu}$ times down the main diagonal; $I_{i}$ is the identity matrix of order the degree of $p_{i}(x)$. Clearly

$$
\sum_{\mu=1}^{k_{i}} \alpha_{i \mu}=\alpha_{i}
$$

Letting $P_{2}=P_{21}+P_{22} \cdots+P_{2 k}$ and $P=P_{1} P_{2}$, we have a direct sum decomposition of $A$ into matrices $A_{i \mu}$ of form (2.3). We shall indicate this by

$$
P^{-1} A P=\ddagger \sum_{i=1}^{k} \sum_{\mu=1}^{k_{i}} A_{i \mu} .
$$

It should be pointed out that the existence of the canonical form (2.3) depends only on the perfectness of the field $F$.

3. Proof of the theorem. Necessity. Suppose $A$ and $B$ have the same characteristic equation

$$
m(x)=\prod\left[p_{i}(x)\right]^{\alpha_{i}}=0
$$

We may then find matrices $P_{a}$ and $P_{b}($ see $\$ 2)$ such that

$$
\begin{aligned}
& P_{a}^{-1} A P_{a}=\dot{+} \sum_{i=1}^{k} \sum_{\mu=1}^{k_{i}} A_{i \mu} \\
& P_{b}^{-1} B P_{b}=\dot{+} \sum_{i=1}^{k} \sum_{\mu=1}^{h_{i}} A_{i \mu}^{*}
\end{aligned}
$$

where $A_{i \mu}$ and $A_{i \mu}^{*}$ (for the same subscript $i$ ) are of the form (2.3) and thus have the same blocks $C_{i}$ on the main diagonal. Moreover $\dot{+} \sum_{\mu=1}^{k_{i}} A_{i \mu}$ and $\dot{+} \sum_{\mu=1}^{h_{i}} A_{i \mu}^{*}$ have the same order since $A$ and $B$ have the same characteristic equation.

Clearly $\dot{+} \sum_{\mu=1}^{k_{i}} A_{i \mu}$ is contained in the algebra of all $\alpha_{i} \times \alpha_{i}$ matrices, with elements in the field $F\left(C_{i}\right)$, whose elements below the main diagonal are 
zero. Noreover,

$$
N_{i}=\mp \sum_{\mu=1}^{k_{i}} A_{i \mu}-\dot{\sum_{\mu=1}} A_{i \mu}^{*}
$$

is in the radical of this algebra since all elements on or below the main diagonal are zero. Thus $g\left(\dot{\sum_{\mu=1}} k_{i \mu}, N_{i}^{\prime}\right)$, for $g$ satisfying the conditions of the theorem, is a radical element and thus nilpotent. lience, letting

$$
N^{1}=N_{1}+N_{2}+\cdots+N_{k}=P_{a}^{-1} A P_{a}-P_{b}^{-1} B P_{b},
$$

we see that $g\left(P_{a}^{-1} A P_{a}, N^{1}\right)$ is nilpotent. Finally, letting

$$
P=P_{b} P_{a}^{-1} \quad \text { and } \quad N=P_{a} N^{1} P_{a}^{-1}=A-P^{-1} B P
$$

we have the result that

$$
P_{a} g\left(P_{a}^{-1} A P_{a}, N^{1}\right) P_{a}^{-1}=g(A, N)
$$

is nilpotent. This completes the proof of the necessity.

Sufficiency. Assume that a $P$ exists such that every polynomial $g$, satisfying the conditions of the theorem, is nilpotent. Define

$$
A_{\theta}=A-\theta N \quad\left(N=A-P^{-1} B P\right),
$$

$m_{\theta}(\lambda)=\left|\lambda I-A_{\theta}\right| \equiv \lambda^{n}+a_{1}(\theta) \lambda^{n-1}+\cdots+a_{n-1}(\theta) \lambda+a_{n}(\theta)$; where $\theta$ is an indeterminate and $a_{i}(\theta)(i=1,2, \cdots, n)$ are polynomials in $\theta$ with coefficients in $F$.

Clearly, $m_{0}(\lambda)=0$ and $m_{1}(\lambda)=0$ are the characteristic equations of $A_{0} \equiv 1$ and $A_{1} \equiv P^{-1} B P$, respectively.

If we now let $\theta$ assume values from $F$ we have

$$
m_{0}\left(A_{\theta}\right)=m_{0}(A)+h_{\theta}(A, N)=h_{\theta}(A, N)
$$

moreover $h_{\theta}(A, N)$ contains $N$ in each term and is nilpotent by hypothesis.

The characteristic roots of $m_{0}\left(A_{\theta}\right)$ are $m_{0}\left(\alpha_{\theta}^{i}\right)(i=1, \cdots, n)$, where the $\alpha_{\theta}^{l}$ are the characteristic roots of $A_{\theta}$. Since $m_{0}\left(A_{\theta}\right)$ is nilpotent we must have

$$
m_{0}\left(\alpha_{\theta}^{i}\right)=0
$$

$$
(i=1, \cdots, n)
$$

From (3.3) it is clearly seen that there can be only a finite number of different 
characteristic equations $m_{\theta}(\lambda)=0$, since all the characteristic roots of $A_{\theta}$ are roots of $m_{0}(\lambda)=0$. Since $F$ is assumed to be infinite, this implies that $a_{i}(\theta)$ is a constant independent of $\theta$. Thus $m_{0}(\lambda) \vDash m_{1}(\lambda)$, and the proof of the sufficiency is complete.

\section{REFERENCES}

1. Alfred Brauer, On the characteristic equations of certain matrices, Bull. Amer. Nath. Soc. 53 (1947), 605-607.

2. W. V. Parker, On matrices whose characteristic equations are identical, Proc. Amer. Nath. Soc. 1 (1950), 464-466.

3. II. T. Reid, A note on the characteristic polynomials of certain matrices, Proc. Amer. Math. Soc. 1 (1950), 584-585.

4. John Williamson, The idempotent and nilpotent elements of a matrix, Amer. J. Nath. 58 (1936), $747-758$.

Lniversity of California, Los Angeles 


\section{PACIFIC JOURNAL OF MATHEMATICS}

\section{EDITORS}

R. M. RoBINSON

University of California Berkeley 4, California

\section{*R. P. Dilworth}

Califomia Institute of Technology Pasadena 4, California

\section{E. F. BECKENBACH, Managing Editor}

University of California

Los Angeles 24, California

*During the absence of Herbert Busemann in 1952.

\section{ASSOCIATE EDITORS}

\author{
R. P. DILWORTH \\ HERBERT FEDERER \\ MARSHALL HALL
}

\author{
P. R. HALMOS \\ HEINZ HOPF
}

R. D. JAMES

\author{
BØRGE JESSEN \\ PAUL LÉVY \\ GEORGE PÓLYA
}

\author{
J. J. STOKER \\ E. G. STRAUS
}

KÖSAKU YOSIDA

\section{SPONSORS}

UNIVERSITY OF BRITISH COLUMBIA

CALIFORNIA INSTITUTE OF TECHNOLOGY

UNIVERSITY OF CALIFORNIA, BERKELEY

UNIVERSITY OF CALIFORNIA, DAVIS

UNIVERSITY OF CALIFORNIA, LOS ANGELES

UNIVERSITY OF CALIFORNIA, SANTA BARBARA

OREGON STATE COLLEGE

UNIVERSITY OF OREGON

\author{
UNIVERSITY OF SOUTHERN CALIFORNIA \\ STANFORD UNIVERSITY \\ WASHINGTON STATE COLLEGE \\ UNIVERSITY OF WASHINGTON \\ AMERICAN MATHEMATICAL SOCIETY \\ NATIONAL BUREAU OF STANDARDS, \\ INSTITUTE FOR NUMERICAL ANALYSIS
}

Mathematical papers intended for publication in the Pacific Journal of Miathematics should be typewritten (double spaced), and the author should keep a complete copy. Manuscripts may be sent to any of the editors. All other communications to the editors should be addressed to the managing editor, E. F. Beckenbach, at the address given above.

Authors are entitled to receive 100 free reprints of their published papers and may obtain additional copies at cost.

The Pacific Journal of Mathematics is published quarterly, in March, June, September, and December, by the University of California, Berkeley 4, California. The price per volume (4 numbers) is $\$ 8.00$; single issues, $\$ 2.50$. Special price to individual faculty members of supporting institutions and to individual members of the American Mathematical Society: $\$ 4.00$ per volume; single issues, $\$ 1.25$.

Subscriptions, orders for back numbers, and changes of address should be sent to the publishers, University of California Press, Berkeley 4, California.

Printed at Ann Arbor, Michigan. Entered as second class matter at the Post Office, Berkeley, California.

\section{UNIVERSITY OF CALIFORNIA PRESS • BERKELEY AND LOS ANGELES}




\section{Pacific Journal of Mathematics}

\section{Vol. 2, No. $2 \quad$ February, 1952}

L. Carlitz, Some theorems on Bernoulli numbers of higher order...

Watson Bryan Fulks, On the boundary values of solutions of the heat equation........................................ 141

John W. Green, On the level surfaces of potentials of masses with fixed center of gravity................................... 147

Isidore Heller, Contributions to the theory of divergent series .......... 153

Melvin Henriksen, On the ideal structure of the ring of entire functions . . . 179

James Richard Jackson, Some theorems concerning absolute neighborhood retracts........................................ 185

Everett H. Larguier, Homology bases with applications to local connectedness ................................... 191

Janet McDonald, Davis's canonical pencils of lines ................ 209

J. D. Niblett, Some hypergeometric identities . . . . . . . . . . . . . . . . . . 219

Elmer Edwin Osborne, On matrices having the same characteristic equation...................................... 227

Robert Steinberg and Raymond Moos Redheffer, Analytic proof of the

Lindemann theorem ................................. 231

Edward Silverman, Set functions associated with Lebesgue area ......... 243

James G. Wendel, Left centralizers and isomorphisms of group algebras . . 251

Kosaku Yosida, On Brownian motion in a homogeneous Riemannian space. 